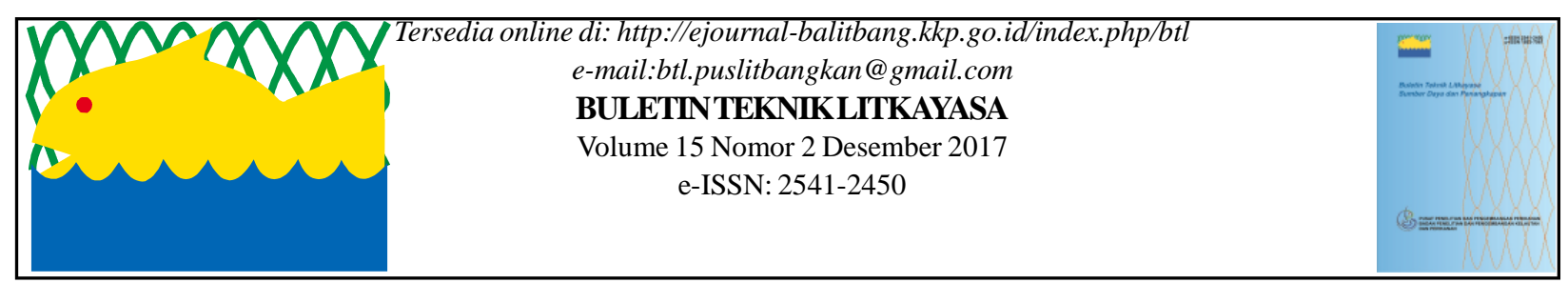

\title{
TEKNIS PENGOPERASIAN BOTTOM TRAWL DENGAN MENGGUNAKAN KR BARUNA JAYA IV DI PERAIRAN ARAFURA
}

\author{
Bambang Witdiarso dan Agus Salim \\ Calon dan Teknisi Litkayasa Balai Penelitian Perikanan Laut \\ Teregistrasi I tanggal: 30 November 2017; Diterima setelah perbaikan tanggal: 08 Desember 2017; \\ Disetujui terbit tanggal: 13 Desember 2017
}

\section{PENDAHULUAN}

Kegiatan pengkajian stok (stock assessment) sumberdaya ikan dan udang merupakan program prioritas pada Balai Penelitian Perikanan Laut dengan tujuan untuk mendapatkan data dan informasi terbaru tentang potensi sumberdaya ikan di perairan Indonesia.

Sumber daya ikan demersal dan udang di perairan Laur Arafura sudah dieksploitasi sejak lama yaitu mulai tahun 1960-1970. Kementerian Kelautan dan Perikanan pada tahun anggaran 2015 sampai dengan 2016 melakukan kegiatan pengkajian stok di seluruh Wilayah Pengelolaan Perikanan (WPP). Menurut Naamin (1984) luas perairan Laut Arafura sekitar $150.000 \mathrm{~km}^{2}$ dengan daerah penangkapan udang mencapai $76.000 \mathrm{~km} 2$, terbagi menjadi daerah penangkapan udang yang utama di sub area Dolak, Kaimana, Aru, Kepala Burung dan Teluk Bintuni.

Laut Arafura merupakan salah satu daerah penangkapan ikan demersal dan udang yang potensial, penangkapan udang dilakukan sangat intensif sepanjang tahun. Untuk mengetahui kondisi terbaru setelah di berlakukannya moratorium, maka Kementerian Kelautan Dan Perikanan melakukan survei pengkajian stok oleh Balai Penelitian Perikanan Laut sebagai pelaksana teknis kegiatan survei dengan menggunakan Kapal Riset Baruna Jaya IV (1219GT). Kapal
dilengkapi dengan bottom trawl.

Tujuan dari penulisan makalah ini adalah untuk mengetahui teknis pengoperasian jaring trawl, komposisi dan jenis sumberdaya ikan demesal dan udang hasil tangkapan trawl di perairanArafura.

\section{POKOKBAHASAN \\ Waktu dan Lokasi}

Kegiatan penelitian di WPP 718 LautArafura dilakukan selama 30 hari mulai tanggal 28 September sampai 27 Oktober 2016. Hari efektif untuk kegiatan pengambilan data di laut Arafura yaitu 12 hari, sementara jumlah hari untuk lintas laut Banda-Arafura 5 hari, lintas lautArafura-Jakarta 11 hari, serta bunker dan perbaikan mesin 2 hari.

\section{Lokasi Sampling}

Posisi sampling penangkapan dengan bottom trawl disusun berdasarkan transek sistematis. Diperoleh 20 stasiun trawl yang menyebar di perairan tenggara Tanjung Ngobar, tenggara Batu Goyang, barat laut P. Irian jaya, barat daya P Fumire, barat laut P Dolak, barat daya P irian Jaya, barat laut Sungai Muli, timur P Semen dan tenggara P Camberu Papuanugini. (Gambar 1).

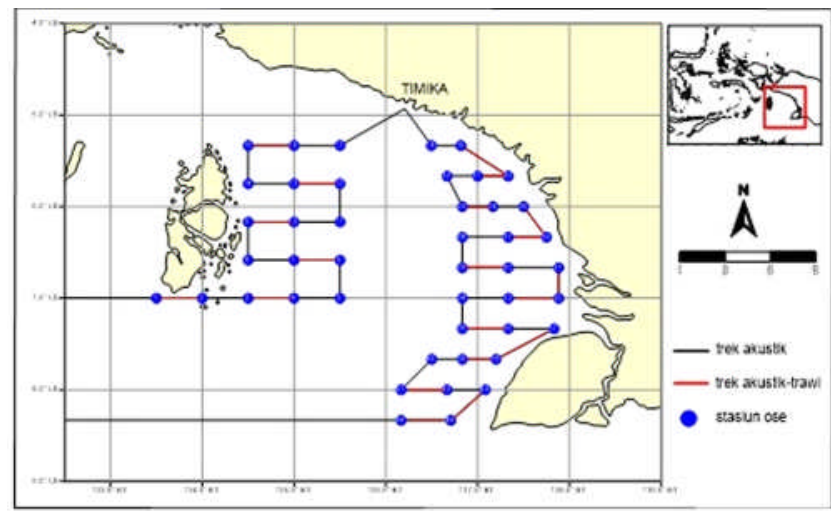

Gambar 1. Penyebaran stasiun penangkapan ikan dengan trawl di perairan Laut Arafura WPP 718, Oktober 2016.

Korespondensi penulis:

Jl. Raya Bogor No.507, Nanggewer Mekar,

Cibinong, Bogor, Jawa Barat-16912 


\section{Armada}

Penelitian menggunakan sarana K.R. Baruna Jaya IV, ukuran 1219 GT, milik BPPT dan ditunjang oleh beberapa alat utama antara lain jaring trawl (bottom trawl) dan perangkat hidro akustik untuk pengkajian stok sumber daya ikan. Selain sumber daya daya ikan, pada kegiatan ini juga dilakukan pengamatan kondisi oseanografi dan aspek biologi ikan sebagai data dukungnya. Alat yang digunakan terdiri dari CTD, plankton net, bongo net, grap dan disecting set.

\section{Alat Tangkap}

Jaring yang digunakan berukuran panjang tali ris atas (head rope) $36 \mathrm{~m}$ dan tali ris bawah (ground rope) $40 \mathrm{~m}$. Bahan utama ris atas maupun ris bawah terbuat dari bahan sling (wire leader) berukuran $\varnothing 12 \mathrm{~mm}$ yang

\section{Bagian}

Sayap Atas dibalut dengan tali PE $2 \mathrm{~mm}$ dan dirangkap dengan tali kuralon $\varnothing 14 \mathrm{~mm}$.

Bahan utama jaring terbuat dari webbing $P E \mathrm{~d} / 42-$ $\mathrm{d} / 48$. Bagian sayap berukuran mata $100 \mathrm{~mm}$, bagian badan berukuran $100 \mathrm{~mm}$ badan $80 \mathrm{~mm}, 60 \mathrm{~mm}$, dan $40 \mathrm{~mm}$. dan kantong $40 \mathrm{~mm}$ d/48. Pelampung yang digunakan jenis tengkorak dari bahan plastik $\varnothing$ $20 \mathrm{~cm}$ sebanyak 15 buah dan pemberat menggunakan rantai besi berukuran $3 / 8$ " dengan berat 150 kg. (Gambar 2.)

Papan pembuka (otter board) berukuran panjang $250 \mathrm{~cm}$ dan lebar $130 \mathrm{~cm}$. Terbuat dari bahan utama kayu damar laut dengan tebal papan $30 \mathrm{~mm}$ dan plat besi sebagai bingkai berukuran $100 \mathrm{~mm} \times 10 \mathrm{~mm}$. Rantai sebagai pengekang berukuran 1 ". Berat papan pembuka sepasang $650 \mathrm{~kg}$. (Gambar 3.)

\section{Bagian \\ Sayap Bawah}

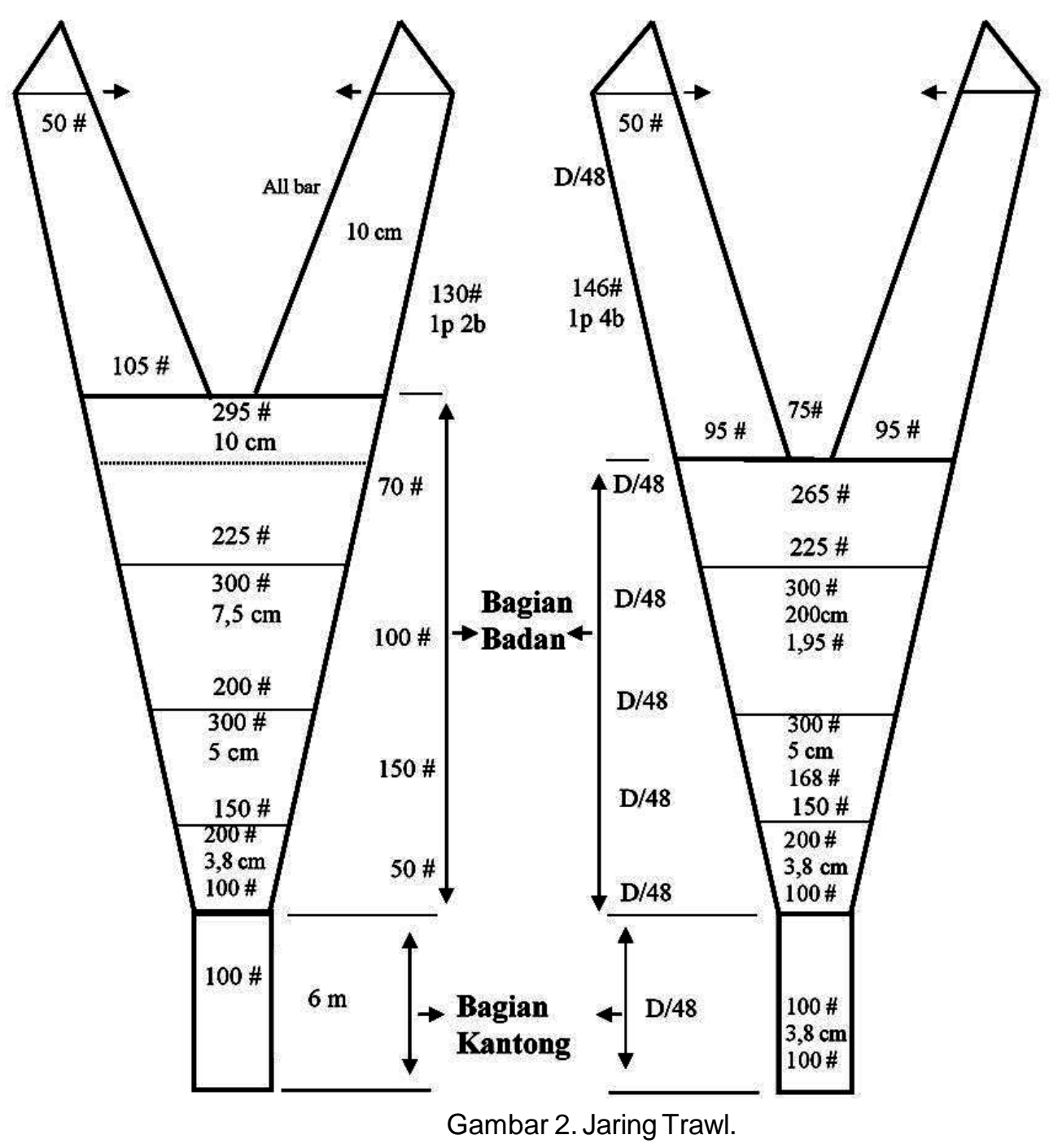




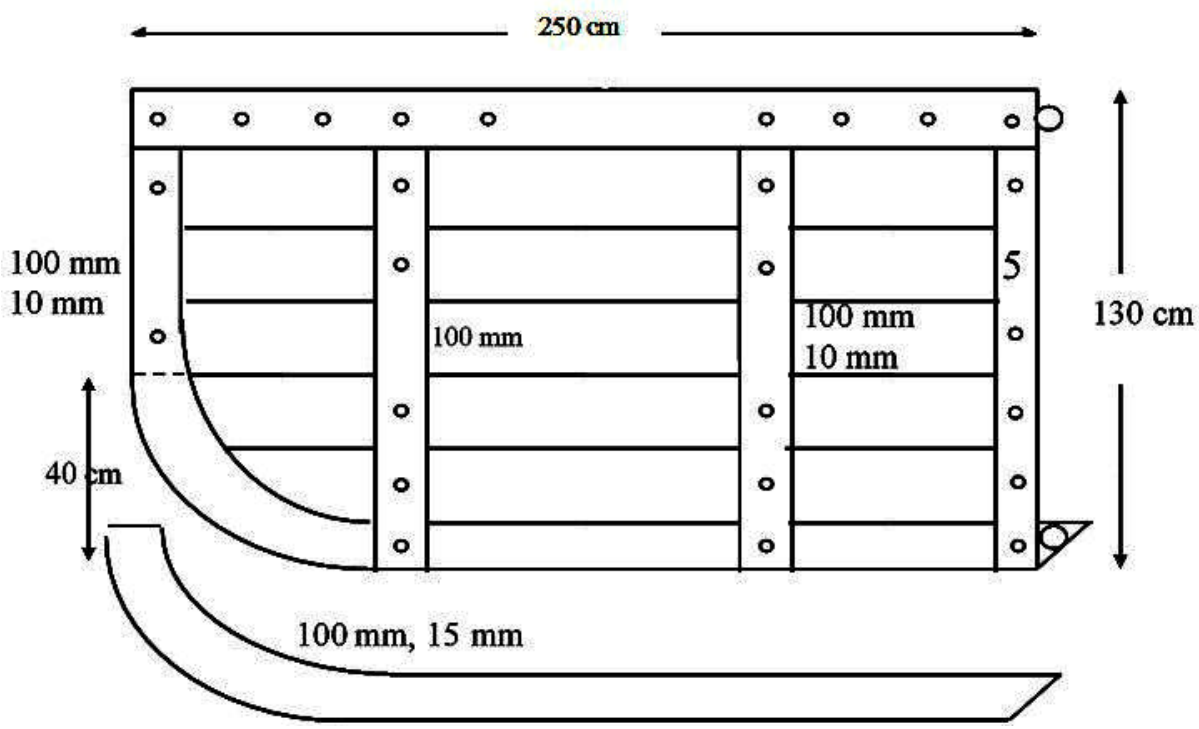

Gambar 3. Otter Board.

Hasil

\section{Pengoperasian Jaring}

Cara pengoperasian jaring trawl tergolong aktif, yaitu dengan cara jaring diturunkan ke laut hingga mencapai dasar perairan, kemudian jaring ditarik dengan tenaga mesin menyapu dasar perairan, (Wudianto dan H.R. Barus, 1993). Panjang tali penarik sangat menentukan keberhasilan operasi penangkapan; biasanya panjang tali penarik berkisar antara 3-4 kali kedalaman perairan, (Ayodhyoa 1986), namun dalam penelitian ini Fissing Mastermenerapkan 4-5kali kedalaman perairan berdasarkan pertimbangan tipe dasar perairan, arus dan gelombang.

\section{Pencatatan Aspek Operasional Trawl}

Pencatatan aspek operasional (Captain bridge sheet) berisi informasi tentang: tanggal, posisi geografis, kedalaman perairan, arah haluan kapal, waktu menarik jaring, kecepatan kapal waktu menarik jaring dan beberapa catatan lainnya. Tabel 1.

Tabel 1. Pencatatan Operasional Jaring Trawl Di KR Baruna Jaya IV Di WPP 718 Oktober 2016 (Captain bridge sheet)

\begin{tabular}{|c|c|c|c|c|c|c|c|c|c|}
\hline TANGGAL & IAM & LOCATION & No.St. & LATITUDE & LONGITUDE & DEPTH (M) & KEDALAMAN & SPEED (knot) & TOWING (jam) \\
\hline 03/10/2016 & 1:26:00 WIT & Tenggara Tg. Ngabor damlu & 1 & $06^{\circ} 59^{\prime} 58^{\prime \prime} \mathrm{S}$ & $134^{\circ} 00^{\prime} 56^{\prime \prime} \mathrm{E}$ & $24-25 m$ & $20-30$ & 3 & 1 \\
\hline $03 / 10 / 2016$ & 6:35:00 WIT & Tenggara P. Batugoyang & 2 & $07^{\circ} 00^{\prime} 088^{\prime \prime} \mathrm{S}$ & $134^{\circ} 15^{\prime} 360^{\prime \prime} \mathrm{E}$ & $20,9-25,8 \mathrm{~m}$ & $20-30$ & 3 & 1 \\
\hline $03 / 10 / 2016$ & 12:06:00 WIT & Utara P. Enu, Laut Arafuru & 3 & $06^{\circ} 59^{\prime} 553^{\prime \prime} \mathrm{S}$ & $134^{\circ} 30^{\prime} 132^{\prime \prime} \mathrm{E}$ & $8,8-11,4 m$ & $10-20$ & 2,5 & 0,37 \\
\hline 04/10/2016 & 5:03:00 WIT & Laut Aru & 4 & $06^{\circ} 59^{\prime} 505^{\prime \prime} \mathrm{S}$ & $135^{\circ} 31^{\prime} 49^{\prime \prime} \mathrm{E}$ & $34-38 m$ & $30-40$ & $2,5-3$ & 1,00 \\
\hline $04 / 10 / 2016$ & $09.00 \mathrm{WIT}$ & Laut Arafuru & 5 & $07^{\circ} 00^{\prime} 077^{\prime \prime} \mathrm{S}$ & $135^{\circ} 39^{\prime} 535^{\prime \prime} \mathrm{E}$ & $34-36 m$ & $30-40$ & 3 & 1 \\
\hline $04 / 10 / 2016$ & 11:15:00 WIT & Laut Aru & 6 & $07^{\circ} 00^{\prime} 119^{\prime \prime} \mathrm{S}$ & $135^{\circ} 49^{\prime} 21^{\prime \prime} \mathrm{E}$ & $36 \mathrm{~m}$ & $30-40$ & 3 & 0,98 \\
\hline $04 / 10 / 2016$ & 14:16:00 WIT & Laut Aru & 7 & $07^{\circ} 00^{\prime} 05^{\prime \prime} \mathrm{S}$ & $135^{\circ} 57^{\prime} 39^{\prime \prime} \mathrm{E}$ & $35-35,7 m$ & $30-40$ & 2,75 & 0,98 \\
\hline 05/10/2016 & 5:26:00 WIT & Laut Aru & 8 & $06^{\circ} 35^{\prime} 17^{\prime \prime} \mathrm{S}$ & $135^{\circ} 27^{\prime} 320^{\prime \prime} \mathrm{E}$ & $23,5-24,2 \mathrm{~m}$ & $20-30$ & 3 & 1 \\
\hline 05/10/2016 & 9:06:00 WIT & Laut Aru & 9 & $06^{\circ} 35^{\prime} 157^{\prime \prime} \mathrm{S}$ & $135^{\circ} 19^{\prime} 37^{\prime \prime} \mathrm{E}$ & $23-23,5 \mathrm{~m}$ & $20-30$ & 3,3 & 1 \\
\hline 05/10/2016 & 12:28:00 WIT & Laut Aru & 10 & $06^{\circ} 34^{\prime} 19^{\prime \prime} \mathrm{S}$ & $135^{\circ} 10^{\prime} 29^{\prime \prime} \mathrm{E}$ & 19 & $10-20$ & 3 & 1 \\
\hline 05/10/2016 & 15:27:00 WIT & Laut Aru & 11 & $06^{\circ} 31^{\prime} 34^{\prime \prime} \mathrm{S}$ & $134^{\circ} 59^{\prime} 42^{\prime \prime} \mathrm{E}$ & $16,9-17 m$ & $10-20$ & 3 & 0,15 \\
\hline 06/10/2016 & 5:13:00 WIT & Laut Aru & 12 & $06^{\circ} 09^{\prime} 347^{\prime \prime} \mathrm{S}$ & $135^{\circ} 30^{\prime} 577^{\prime \prime} \mathrm{E}$ & $40,3-42,5 \mathrm{~m}$ & $40-50$ & 3 & 0,95 \\
\hline 09/10/2016 & 3:35:00 WIT & Laut Aru & 13 & $05^{\circ} 01^{\prime} 47^{\prime \prime} \mathrm{S}$ & $136^{\circ} 48^{\prime} 43^{\prime \prime} E$ & $38-43 m$ & $40-50$ & 3 & 1,01 \\
\hline 09/10/2016 & 14:57:00 WIT & Laut Aru & 14 & $05^{\circ} 19^{\prime} 42^{\prime \prime} \mathrm{S}$ & $135^{\circ} 57^{\prime} 49^{\prime \prime} E$ & $51 \mathrm{~m}$ & $50-60$ & 2,85 & 1 \\
\hline $10 / 10 / 2016$ & 6:13:00 WIT & Laut Aru & 15 & $05^{\circ} 23^{\prime} 00^{\prime \prime} \mathrm{S}$ & $134^{\circ} 49^{\prime} 495^{\prime \prime} \mathrm{E}$ & $34,5-40,3 \mathrm{~m}$ & $30-40$ & 3 & 1 \\
\hline $10 / 10 / 2016$ & 12:00:00 WIT & Laut Aru & 16 & $05^{\circ} 39^{\prime} 01^{\prime \prime} \mathrm{S}$ & $134^{\circ} 54^{\prime} 09^{\prime \prime} \mathrm{E}$ & $17 \mathrm{~m}$ & $10-20$ & 3,5 & 1 \\
\hline $11 / 10 / 2016$ & 4:00:00 WIT & Laut Aru & 17 & $05^{\circ} 45^{\prime} 30^{\prime \prime} \mathrm{S}$ & $136^{\circ} 02^{\prime} 05^{\prime \prime} \mathrm{E}$ & $44,40-47,20 \mathrm{~m}$ & $40-50$ & 3,1 & 1 \\
\hline $11 / 10 / 2016$ & 12:03:00 WIT & Laut Aru & 18 & $05^{\circ} 52^{\prime} 464^{\prime \prime} \mathrm{S}$ & $136^{\circ} 41^{\prime} 126^{\prime \prime} \mathrm{E}$ & $43-46,3 m$ & $40-50$ & 3 & 1 \\
\hline $12 / 10 / 2016$ & 5:16:00 WIT & Tenggara P.Cambera & 19 & $06^{\circ} 01^{\prime} 182^{\prime \prime} \mathrm{S}$ & $138^{\circ} 02^{\prime} 33^{\prime \prime} \mathrm{E}$ & $18,70-20,50 \mathrm{~m}$ & $20-30$ & 3 & 0,25 \\
\hline $12 / 10 / 2016$ & 11:53:00 WIT & Barat daya Irian Jaya & 20 & $06^{\circ} 20^{\prime} 394^{\prime \prime} \mathrm{S}$ & $138^{\circ} 15^{\prime} 529^{\prime \prime} \mathrm{E}$ & $10,2-12,9 \mathrm{~m}$ & $10-20$ & 3 & 1,01 \\
\hline $12 / 10 / 2016$ & 18:23:00 WIT & Barat Laut P.Irian Jaya & 21 & $06^{\circ} 23^{\prime} 212^{\prime \prime} \mathrm{S}$ & $137^{\circ} 48^{\prime} 24^{\prime \prime} E$ & $37,80-42,30 \mathrm{~m}$ & $40-50$ & 3 & 1,01 \\
\hline $13 / 10 / 2016$ & 7:08:00 WIT & Timur P.Semen Irian Jaya & 22 & $06^{\circ} 43^{\prime} 020^{\prime \prime} \mathrm{S}$ & $137^{\circ} 41^{\prime} 440^{\prime \prime} \mathrm{E}$ & $25,90-27,10 \mathrm{~m}$ & $20-30$ & 2,7 & 1 \\
\hline $13 / 10 / 2016$ & 17:13:00 WIT & Barat Daya P.Fumire & 23 & $06^{\circ} 43^{\prime} 546^{\prime \prime} \mathrm{S}$ & $138^{\circ} 26^{\prime} 19^{\prime \prime} \mathrm{E}$ & $9,0-9,8 \mathrm{~m}$ & $<10$ & 2,7 & 1 \\
\hline $13 / 10 / 2016$ & 22:42:00 WIT & Barat Laut S.Muli & 24 & $07^{\circ} 02^{\prime} 034^{\prime \prime} \mathrm{S}$ & $138^{\circ} 21^{\prime} 21^{\prime \prime} \mathrm{E}$ & $13,1-15,1 \mathrm{~m}$ & $10-20$ & 3 & 1 \\
\hline $14 / 10 / 2016$ & 7:58:00 WIT & Barat Laut P.Dolak & 25 & $07^{\circ} 20^{\prime} 321^{\prime \prime} \mathrm{S}$ & $138^{\circ} 18^{\prime} 580^{\prime \prime} \mathrm{E}$ & $10,40-12,0 \mathrm{~m}$ & $10-20$ & 2,5 & 1 \\
\hline $14 / 10 / 2016$ & 18:43:00 WIT & Laut Aru & 26 & $07^{\circ} 22^{\prime} 060^{\prime \prime} \mathrm{S}$ & $137^{\circ} 20^{\prime} 477^{\prime \prime} \mathrm{E}$ & $26,30-28,80 \mathrm{~m}$ & $20-30$ & 2,5 & 1 \\
\hline
\end{tabular}




\section{Tahap penawuran jaring (setting)}

Pengoperasian trawl dimulai dengan mempesiapkan jaring dan beberapa alat bantu. Pemasangan tali-temali, seperti ikatan tali kantong jaring, pemasangan kedua ujung sayap jaring pada tali penghubung antara jaring dan outher board; outher board dengan winch di kapal terpasang sempurna. Sebelum jaring diturunkan terlebih dahulu ditaksir kedalaman perairan, ini mutlak diperlukan karena untuk menentukan seberapa panjang tali penarik yang diperlukan. Tak kalah penting adalah mengetahui type dasar perairan, memungkinkan atau tidak untuk dilakukan trawlling. Untuk itu sebelum jaring diturunkan dilakukan penyisiran terlebih dahulu dengan echo sounder untuk mengetahui type dasar perairan. Operasional Trawl baru bisa dilakukan setelah diketahui bahwa perairan tersebut dan benarbenar aman untuk dilakukan trawlling.

Dengan kecepatan kapal 4-5 knot jaring diturunkan terlebih dahulu adalah bagian kantong, kemudian seluruh badan jaring dan sayap jaring hingga tali penghubung jaring dan outher board. Setelah bukaan jaring kelihatan sempurna di atas permukaan air, kemudian outher board diturunkan di bawah permukaaan air. Setelah ke 2 outher board kelihatan sempurna, tali penarik (wrap) di ulur sesuai kebutuhan yang disesuaikan dengan kedalaman. Kecepatan putaran winch tidak lebih dari kecepatan kapal untuk menjaga outher board tetap berdiri. Kemudian dilakukan penarikan (towing) selama kira-kira 60 menit dengan kecepatan rata-rata 3 knot.

Selain ukuran panjang tali penarik faktor lain yang sangat menentukan keberhasilan operasional trawl adalah Kecepetan kapal. Kalau kapal terlalu cepat, trawl bisa melayang. Sedangkan kalau kapal terlalu pelan, trawl bisa membenam kelumpur dan akhirnya akan mengurangi bukaan jaring. (Wudianto dan H.R. Barus, 1993).

Selain faktor kecepatan kapal dan panjang tali penarik berat jaring itu sendiri di dalam air juga sangat menentukan keberhasilan operasional trawl. Dengan berat jaring tertentu bila ditarik dengan kecepatan kapal lebih tinggi dan tali penarik kurang panjang jaring akan melayang,bila ditarik dengan kecepatan kapal rendah dan tali penarik terlalu panjang maka jaring akan terlalu mendasar. Kegiatan trawling dilakukan di perairan yang relatif datar dengan kedalaman $10 \mathrm{~m}$ sampai $40 \mathrm{~m}$. Gambar 4 .

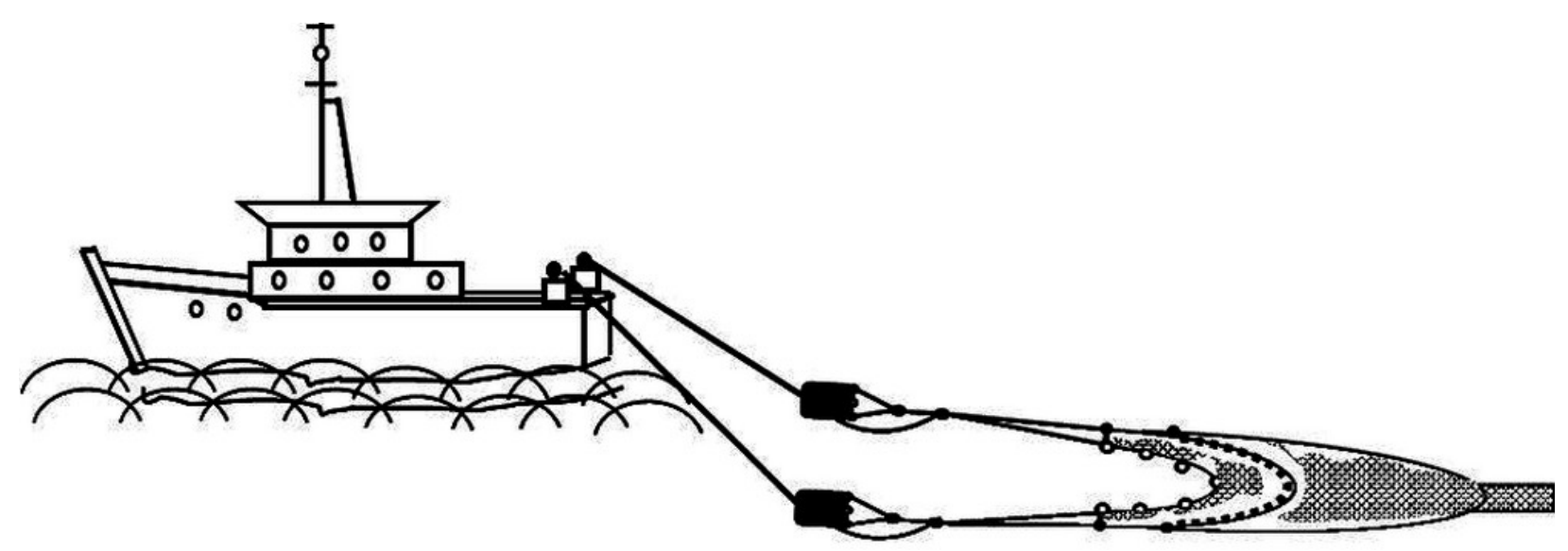

Gambar 4. Pengoperasian jaring trawl.

Secara keseluruhan diperoleh 10 stasiun penangkapan ikan, terdiri dari 5 stasiun penangkapan di perairan barat daya Papua (sub area Dolak dan Kokonao) dan 5 stasiun penangkapan di perairan sebelah timur Aru.

\section{Tahapan-tahapan dalam pengangkatan Jaring (hauling)}

Setelah dilakukan penarikan jaring (towing) selama 60 menit, kapal mengurangi kecepatannya 1-2 knot. Kemudian winch dihidupkan untuk manarik/ menggulung tali penarik hingga Otter board niak sampai ke blok yang berada di kanan kiri buritan kapal. Outher board ditahan menggantung dengan rantai dan segel. Tali bantu dilepas dan dipasang pada tali penarik yang terhubung dengan net drum. Net drum dihidupkan menarik/menggulung jaring hingga kantong jaring naik dibagian tengah buritan kapal, kemudian kantong jaring diangkat dengan kren; akhirnya tali kantong dilepas untuk mengeluarkan hasil tangkapan.

\section{Memisahkan Hasil Tangkapan (sortir)}

Hasil tangkapan kemudian ditumpahkan digeladak kapal bagian belakang untuk memisahkannya dari 
sampah lumpur dan karang. Ikan disortir berdasarkan genus dan family. Setelah disortir berdasarkan genus dan famili, kemudian ikan disortir berdasarkan spesies, ditimbang dan dihitung jumlahnya. Untuk spesies tertentu (dominan) dilakukan pengukuran, panjang, berat, dan TKG.

\section{Komposisi Hasil Tangkapan}

Identifikasi ikan dilakukan di atas kapal segera setelah selesai penyortiran yaitu sampai ke tingkat jenis (spesies), marga (genus) dan suku (family), dengan mengacu kepada Gloefer-Tarp \& Kailola (1985) dan Nakabo (2000). Identifikasi udang menggunakan acuan Grey et al. (1983).

Sumberdaya ikan yang tertangkap dengan trawl di Wilayah Pengelolaan Perikanan (WPP) 718 Perairan Arafura terdiri dari ikan demersal, pelagis kecil, cumi/sotong (cephalopoda), udang penaeid, udang mantis (stomatopod), pari, kepiting/rajungan (crabs), hiu dan jenis sumber daya lainnya.

Tabel 2. Komposisi sumber daya ikan yang tertangkap trawl di perairan Arafura WPP 718 Oktober 2016 (20 stasiun).

\begin{tabular}{|c|l|c|}
\hline No & \multicolumn{1}{|c|}{ Sum berdaya Ikan } & Berat (kg) \\
\hline 1 & Demersal & 2503 \\
2 & Pelagis & 223 \\
3 & Cephalopoda & 117 \\
4 & Udang & 109 \\
5 & Pari & 98 \\
6 & Krustasea & 60 \\
7 & Hiu & 29 \\
\hline \multicolumn{1}{|c|}{ Total } \\
\hline
\end{tabular}

\section{KESIMPULAN}

Kapal Baruna Jaya IV merupakan kapal riset perikanan sehingga secara teknis lebih effisien untuk operasional alat tangkap trawl. Perairan Arafura merupakan daerah yang layak untuk pengoperasian trawl, terlihat dari suksesnya kegiatan trawlling. Komposisi hasil tangkapan di dominasi ikan demersal, pelagis, cephalopoda, udang.

\section{PERSANTUAN}

Penulis berterimakasih kepada penanggung jawab WPP ketua tim pelayaran Baruna Jaya IV para peneliti dan teknisi yang telah membantu dalam penulisan ini.Tulisan ini merupakan kontribusi dari hasil kegiatan survei pendugaan stok ikan di perairan Arafura tahun 2016.

\section{DAFTAR PUSTAKA}

Ayodhyoa. (1986). Tehnik penangkapan ikan. Yayasan Dewi Sri, Bogor.

Gloerfelt-Tarp, T. \& P. Kailola. (1985). Trawled fish of the southern Indonesia and northern Australia. ADAB -GTZ-DGF Indonesia : xvi + $406 \mathrm{hlm}$.

Naamin. (1992). Pedoman teknis pemanfaatan dan pengelolaan sumber daya udang penaeid bagi pengembangan perikanan. Seri Pengembangan Penelitian Perikanan No. PHP/KAN/PT/22/1992. Badan Litbang Pertanian: 92 hal.

Wudianto \& H.R. Barus. (1993). Jurnal Perikanan Laut. (77), 92-106. 